Canadian

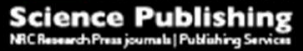

Botany

Botanique

\title{
Floral organogenesis in Urophysa rockii, a rediscovered, endangered and rare species of Ranunculaceae
}

\begin{tabular}{|r|l|}
\hline Journal: & Botany \\
\hline Manuscript ID & cjb-2015-0232.R1 \\
\hline Manuscript Type: & Article \\
\hline Date Submitted by the Author: & 16 -Dec-2015 \\
\hline Complete List of Authors: & $\begin{array}{l}\text { Zhao, Liang; College of Life Sciences, Northwest A\&F University, Yangling } \\
\text { 712100, China. } \\
\text { Gong, Jing-zhi ; College of Life Sciences, Northwest A\&F University } \\
\text { Zhang, Xiao-hui; College of Life Sciences, Shaanxi Normal University, Xi'an } \\
\text { 710062, China. } \\
\text { Liu, You-quan; Mianyang Preschool Educators College, Sichuan Normal } \\
\text { University, Jiangyou 621709, China. } \\
\text { Ma, Xiao; College of Life Sciences, Northwest A\&F University, Yangling } \\
\text { 712100, China. } \\
\text { Ren, Yi; College of Life Sciences, Shaanxi Normal University, Xi'an 710062, } \\
\text { China. }\end{array}$ \\
\hline Keyword: & floral development, floral morphology, Ranunculaceae, Urophysa \\
\hline \multicolumn{2}{|c}{} \\
\hline
\end{tabular}

SCHOLARONE ${ }^{\text {w }}$

Manuscripts 
Floral organogenesis in Urophysa rockii, a rediscovered, endangered and rare species of

\section{Ranunculaceae}

Liang Zhao ${ }^{1, *}$, Jing-zhi Gong ${ }^{1}$, Xiao-hui Zhang ${ }^{2}$, You-quan Liu $^{3}$, Xiao Ma ${ }^{1}$, Yi Ren $^{2}$

Running title: Zhao et al.- Floral organogenesis in Urophysa

1 Liang Zhao, Jing-zhi Gong, and Xiao Ma College of Life Sciences, Northwest A\&F

University, Yangling 712100, China.

Liang Zhao, Email: biology_zhaoliang@126.com; Jing-zhi Gong, Email: 1471572926@qq.com;

Xiao Ma, Email: 1198400120@qq.com

2 Xiao-hui Zhang and Yi Ren College of Life Sciences, Shaanxi Normal University, Xi'an 710062, China.

Xiao-hui Zhang, Email: xhzhang@snnu.edu.cn; Yi Ren, Email: renyi@snnu.edu.cn

3 You-quan Liu, Mianyang Preschool Educators College, Sichuan Normal University, Jiangyou 621709, China.

Email: $\underline{\text { 222807479@qq.com }}$

\section{*Author for correspondence:}

Liang Zhao, E-mail: biology_zhaoliang@,126.com; Phone (Fax) number: +86-029-87092262 
Abstract: Urophysa is an Asian endemic genus in the Ranunculaceae, but floral organogenesis data, which will be a useful complement to molecular data in clarifying the relationship with close related taxa (Aquilegia and Semiaquilegia) in Ranunculaceae, are completely lacking. We used scanning electron microscopy and light microscopy to study floral development of Urophysa rockii, a recently rediscovered species in this genus. The sepals are initiated spirally, while other organs are non-simultaneously whorled. The floral phyllotaxis is whorled. Primordia of the sepals are lunular and truncate, but those of the petals and stamens are hemispherical, rounded. After sepal initiation, there is a delay in development, but the initiation of petals and stamens is continuous. The developmental sequence of the microspores in the stamens is centrifugal, although the stamens are initiated centripetally. The early developmental stages of the staminodes are similar to those of the stamens, although much smaller, so they may be phylogenetically homologous organs. The carpel primordia are lunular in shape and plicate. The mature ovule is anatropous and bitegmic. Urophysa shows similar floral development features as Aquilegia and Semiaquilegia, although with some differences, which supports their relationship inferred by DNA sequence data.

Keywords: floral development; floral morphology; Ranunculaceae; Urophysa 


\section{Introduction}

The Chinese endemic genus Urophysa (Ranunculaceae) consists of two species, Urophysa henryi (Oliver) Ulbrich and Urophysa rockii Ulbrich, both distributed on cliffs or fissures of rocks by streams in southern China (Wang et al. 2001). The former species has been placed in Isopyrum, Aquilegia or Semiaquilegia successively (Drummond and Hutchinson 1920). In 1925, J. F. Rock, an American plant collector, discovered the latter Urophysa species for the first time on moist, mossy banks along the Fujiang River in Jiangyou County, in western Sichuan Province, China. In 1929, Eberhard Ulbrich formed a new genus Urophysa based on Isopyrum henryi Oliver = Semiaquilegia henryi (Oliver) Drummond et Hutchinson. This new genus included Urophysa henryi (Oliver) Ulbrich and U. rockii Ulbrich, with "rockii" in memory of J. F. Rock (Ulbrich 1929).

U. rockii had not been collected after 1925 until Dr. Chunyu Li found it again 80 years later in Jiangyou County of western Sichuan Province in 2005 (Du and Yang 2010). Unfortunately, there are only about 2000 individuals in four populations surviving in the upper reaches of Fujiang River. To preserve the species, the government moved most of the individuals to a new habitat in Jiangyou County in the year 2011, because their original habitats would be completely submerged by the Wudu Reservoir project.

The Ranunculaceae, as one of the core families in the Ranunculales, belongs to the early-diverging eudicots and is considered as a transitional group between basal angiosperms and core eudicots (APG 2003). This in-between group is diverse in its floral characters. Over the past 20 years, molecular phylogenetic studies have contributed greatly to the resolution of phylogenetic relationships within the Ranunculaceae and thus to the continuous improvement of their 
systematics and taxonomy (Wang et al. 2009). In subfamily Thalictroideae of Ranunculaceae, three major groups were recognized by molecular data (1) Thalictrum, Leptopyrum, Paropyrum, and Paraquilegia; (2) Urophysa, Semiaquilegia, and Aquilegia; and (3) Dichocarpum, Enemion, and Isopyrum (Wang and Chen 2007; Wang et al. 2009). At the same time, tremendous progress has been made in understanding the floral organogenesis of Ranunculaceae, including floral morphology and development (Endress 1995; Wang and Ren 2008; Ren et al. 2009, 2010, 2011; Zhao et al. 2011, 2012a, b, and references therein; Erbar and Leins 2013; Erbar 2014). The Thalictroideae offers a wealth of opportunities to study comparative floral development both in morphology and gene expression (Tucker and Hodges 2005). However, floral organogenesis of the Thalictroideae has been reported for only a few genera (Aquilegia, Semiaquilegia, Enemion, Dichocarpum and Thalictrum) (Feng et al. 1995; Tucker and Hodges 2005; Ren et al. 2011). In the Urophysa-Semiaquilegia-Aquilegia group, flowers of Aquilegia possess morphological innovations, namely elaborate petal spurs and staminodes which are located between stamens and carpels, that are well suited to the investigation of key questions about evolutionary development. Aquilegia has become a new model for studies of plant development, ecology, and evolution (Hodge 1997; Kramer 2009; Sharma et al. 2014). In contrast to knowledge about Aquilegia, a detailed study of the floral organogenesis of Urophysa, which may be of great help in elucidating its systematic affinities within Ranunculaceae, had not been conducted. Since the species was rediscovered, however, studies have been done on its habitat (Liu et al. 2007, 2009; Du et al. 2010), vegetative anatomy (Wang and He 2011; Wang et al. 2011), genetic diversity (Zhang et al. 2013a) (Zhang et al. 2013b) and seed dispersal and germination.

The aims of the present study were to (1) determine the floral morphology and development 
of Urophysa rockii and (2) compare the results with those of related genera in the Ranunculaceae.

\section{Materials and methods}

Flower buds and anthetic flowers of $U$. rockii were collected at all stages of development from October 2009 to March 2010 at Xiangjiagou, Mountain Longmen, Jiangyou County, Sichuan Province, China (alt. 950 m, voucher: ZhaoLiang SC20091001, SANU). The collection was conducted in concordance with all applicable laws. All materials were fixed in FAA

(Formalin-acetic acid-ethanol-water $=10: 5: 50: 35)$.

For SEM (scanning electron microscope) studies, 60 floral buds were dissected and dehydrated in an ethanol and iso-amyl acetate series, critical-point dried in $\mathrm{CO}_{2}$, and then sputter-coated with gold. SEM micrographs were taken with a HITACHI S-4800 or S-3500 scanning electron microscope.

For light microscopy (LM) studies, flowers at different developmental stages were dehydrated in an alcohol and propylene oxide series and embedded in Epon812. Twenty embedded floral buds were sectioned at $1-2 \mu \mathrm{m}$. The sections were stained with $0.1 \%$ toluidine blue in $\mathrm{dH} 2 \mathrm{O}$ $(\mathrm{w} / \mathrm{v})$ and examined with a Leica DMLB microscope. Other flower material was embedded in paraffin, sectioned 6-8 $\mu \mathrm{m}$ thick, and stained with hematoxylin.

Photographs of mature flowers were taken with a Nikon Coolpix S8000 digital camera (Figs. 1B and 1C). The description of the floral morphology is based on 15 mature flowers. The symbols used in the floral diagrams and floral formulae followed Ronse De Craene (2010) and Prenner et al (2010). 


\section{Results}

\section{Flower morphology}

The 15 anthetic flowers were ca. $2 \mathrm{~cm}$ in diameter, terminal and solitary, bisexual and polysymmetric (Figs. 1B and 1C). The perianth was comprised of 5 sepals and 5 petals. The sepals were blue to white, obovate to broadly elliptic, and ca. $20 \mathrm{~mm}$ long. The petals were yellow, elliptic navicular, with obtuse apex, ca. $6 \mathrm{~mm}$ long with a ca. $2 \mathrm{~mm}$ long spur. In the center of the flower, there were 10 lanceolate staminodes, 30 stamens, and 5 carpels. All organs were free (Figs. $1 \mathrm{~B}$ and $1 \mathrm{C})$.

\section{Floral phyllotaxis and organ initiation}

Sepal primordia are initiated in a clockwise or counterclockwise spiral sequence with an average divergence angle of ca. $137^{\circ}$ between two successive primordia, and they are broad, crescent-shaped, and truncate (Fig. 2A). The plastochron is relatively long between the last sepal and the first petal (Fig. 2B). The floral apex enlarges considerably and remains a highly convex dome shape throughout the period of development (Figs. 2C-G). The petal, stamen, staminode, and carpel primordia are initiated as non-simultaneous whorls with a relatively short plastochron, and they are very similar in shape at the very young stages of development, i. e. narrow, hemispherical, and round (Figs. 2B-G). The stamens form ten regular alternate orthostichies, which include five petal-based and five sepal-based stamens. The staminode primordia appear at the top of each orthostichy, and they resemble the stamen primordia but are much smaller (Figs. 2E-G) and flatter (Fig. 4A). The five carpel primordia appear almost synchronously (Fig. 2G), after which a residual floral apex remains but is later hidden by the developing carpels (Figs. 
$2 \mathrm{G}-\mathrm{J})$.

In later developmental stages, the young sepals enlarge and enclose all the other floral organs

(Fig. 2K). In contrast, the development of the petals is delayed, and they expand after the stamens are differentiated into anthers and filaments (Figs. $2 \mathrm{~K}$ and 2L). Petals are at first disk-like, then a depression appears in the middle ventral portion of the petal (Fig. 3A). Two inconspicuous bulges appear and soon fuse with the margin of the petal to form a transverse ridge (Fig. 3B). With the depression becoming much deeper, a pocket-like spur is formed gradually (Figs. 3C, 4C-4E). Each spur elongates, and nectariferous tissue forms inside the spur (Figs. 3D, 4B and 4F).

Each young stamen quickly differentiates into a long filament and a much shorter anther (Fig. 3E). The anthers are basifixed and have longitudinal dehiscence (Fig. 3F). There are some special stamens with broad and wrinkled filaments (Fig. 3G), which are similar to the staminodes (Figs. 3I-3K). The pollen is tricolpate (Fig. 3H). From histological observations of three stamens in a longitudinal series (Fig. 5A), we determined that the sequence of microsporogenesis is centrifugal, because the innermost stamen $\left(\mathrm{St}_{1}\right)$ had pollen grains (Fig. $\left.5 \mathrm{~b}\right)$, the second one $\left(\mathrm{St}_{2}\right)$ was in the post tetrad stage (Fig. 5C), and the outmost one ( $\left.\mathrm{St}_{3}\right)$ had tetrads (Fig. 5D).

The development of the carpel is plicate. First, a median longitudinal groove appears on the ventral side of each young carpel, causing it to become horseshoe-shaped (Fig. 3L). The carpel margins expand and become appressed early, but the suture remains visible externally and extends the full length up to the stigma (Fig. 3M). Later, the dorsal side of the carpel becomes rounded and the distal part elongates into an attenuate style and stigma (Figs. 3N and 3O). As the style becomes slightly reflexed backwards, a decurrent stigma covered with unicellular papillae differentiates on the margins of the carpel tip (Fig. 3P). 
Ovule primordia are initiated along the margins of the carpel, and they are arranged like the teeth of a zipper (Fig. 6A). As each young ovule elongates, it gradually becomes digitate. The inner integument is initiated at mid-length and forms a regular ring (Fig. 6B). The ovule plus the funiculus start to bend inwards (Fig. 6C), and the outer integument is initiated beneath the inner integument shortly after (Fig. 6D). The ovules bend further downwards. The inner integument remains annular, whereas the outer integument is obviously semi-annular (Fig. 6E). With the development of the ovule, the rim of the inner integument becomes slightly lobed (Figs. 6D and 6E), and the lobes become obvious in the mature ovule (Fig. 6I). As the outer integument gradually becomes hood-shaped, an appendage consisting of unicellular papillae appears at the base of the ventral side of the funiculus and on the placenta (Fig. 6F). Later, the appendage extends along the lateral sides of the funiculus and becomes thicker on the placenta. The appendage on each ovule enlarges, fuses with that of the neighbouring ovule, and finally becomes a raphe-shaped appendage on the placenta that surrounds the funiculus (Figs. 6G and 6H). The mature ovule is anatropous and bitegmic, and it is almost parallel to the funiculus and completely fuses with it. The micropyle is formed by a four-lobed inner integument, and the rim of the outer integument also is slightly lobed (Figs. $4 \mathrm{H}$ and $4 \mathrm{I}$ ).

\section{Discussion}

\section{Aspects of flora development}

The sepals in Urophysa rockii are initiated spirally, but the initiation sequence of other organs is whorled. However, the five petals have different sizes in the early developmental stages. The same situation occurs in the stamens and ten staminodes. Therefore, the initiation sequence of petals, 
stamens and staminodes in U. rockii is non-simultaneous whorled, which is similar to Aquilegia yabeana (Ren et al. 2011). The floral phyllotaxis in Urophysa rockii is whorled, which is the same as in other genera of Thalictroideae (Schöffel 1932; Feng et al. 1995; Tucker and Hodges 2005; Ren et al. 2011).

The most variable organs in the flowers of Ranunculaceae are the so-called petals, which are inserted between the petaloid sepals and stamens, serving in nectar production and nectar presentation. The petals are one of the most important diagnostic characters within the family (Tamura 1995). The special nectary organs have been investigated developmentally in a number of studies (Hiepko 1965; Kosuge and Tamura 1989; Erbar et al. 1998; Ren et al. 2011; Zhao et al. 2012a; Erbar and Leins 2013; Erbar 2014). Their shapes can vary considerably: tubular (Helleborus, Zhao et al. 2011), flat (with the basal nectary pit mostly covered with a scale, e.g. Ranunculus, Zhao et al. 2012a; Erbar and Leins 2013), peltate (Asteropyrum, Zhao et al. 2012b) or spurred (Aquilegia and Semiaquilegia, Ren et al. 2011). In Urophysa rockii, the petals are spurred, with the nectary tissue secreted at the base, which is similar to Semiaquilegia (Tucker and Hodges 2005), Aquilegia (Ren et al. 2011) and Nigella (Zhao et al. 2011).

The present observations of the floral organogenesis of $U$. rockii and SEM studies in some other genera of Ranunculaceae (Kosuge 1994; Endress 1995; Feng et al. 1995; Erbar et al. 1998; Tucker and Hodges 2005; Ren et al. 2009, 2010, 2011) clearly show a relatively long plastochron between the last initiated sepal and the first petal, but shorter and equal plastochrons between the primordia of the petals and stamens. The sepal primordia are crescent-shaped and truncated, whereas those of the petals and stamens are hemispherical and rounded and similar in the early stages of development. The similarity between the primordia of petals and stamens support the 
possible evolutionary relationship between the petals and stamens in the Ranunculaceae (Zhao et al. 2011).

The anther maturation sequence is centripetal in most Ranunculaceae (e.g. Caltha and Trollius, Song et al. 2007; Adonis and Callianthemum, Ren et al. 2009; Clematis, Ren et al. 2010; Helleborus and Nigella, Zhao et al. 2011; Thalictrum and Dichocarpum, Ren et al. 2011) but can be centrifugal (Aquilegia, Tepfer 1953; Feng et al. 1995; Ren et al. 2011) or sometimes bidirectional (Anemone, Chang et al. 2005; Ren et al. 2010). In Urophysa rockii, the maturation direction of the stamens is opposite to that of their initiation, and thus the direction of maturation is centrifugal, which is similar to Aquligia (Tepfer 1953; Feng et al. 1995; Ren et al. 2011).

The staminodes of Aquilegia and Semiaquilegia, which are positioned above the stamens and around the carpels, are called "inner staminodes" (Ronse De Craene et al. 2003) or "staminodia" (Sharma et al. 2014). Staminodes have been presumed to protect the early developing fruits (Voelckel et al. 2010; Sharma et al. 2014). In Urophysa rockii, the position of the staminodes is similar to Aquilegia and Semiaquilegia, with five staminodes surrounding the carpel whorl. In the early developmental stages, staminodes of $U$. rockii are similar to the stamens as found in Aquilegia and Semiaquilegia, so they may be phylogenetically homologous organs (Ren et al. 2011).

Ovule morphogenesis characteristics are significant in classification at the levels of subfamilies, tribes and some genera of Ranunculaceae (Wang and Ren 2008). Wang and Chen (2007) recognized three major groups within Thalictroideae: (1) Thalictrum, Leptopyrum, Paropyrum, and Paraquilegia; (2) Urophysa, Semiaquilegia, and Aquilegia; (3) Dichocarpum, Enemion, and Isopyrum (Wang and Chen 2007). Ovule morphogenesis studies showed that 
Thalictrum, Aquilegia and Dichocarpum are obviously different from each other, although their mature ovules are all anatropous and bitegmic (Wang and Chen 2007). In Dichocarpum, the appendage appears on the upper part of the ventral side of the funiculus, and about two-thirds of the funiculus fuses with the ovule body. In Aquilegia and Thalictrum the appendage appears from the placenta and the funiculus, and the funiculus completely fuses with the ovule body; the inner integument in Thalictrum is longer than the outer one (Wang and Ren 2008). In Urophysa, the appendage appears from the placenta and the funiculus, and the outer integument is longer than the inner one, which is similar to Aquilegia and Semiaquilegia (personal observations by L Z, Table 1). Therefore, we agree with the opinion that Aquilegia, Semiaquilegia and Urohpysa have close genetic relationships (Wang and Chen 2007).

\section{Urophysa has a close relationship to Aquilegia and Semiaquilegia}

Our study showed that a close affinity of Urophysa with Aquilegia and Semiaquilegia is supported by several floral developmental and morphological features: (1) whorled floral phyllotaxis; (2) broad and crescent-shaped young sepals; (3) a relatively long plastochron between the last sepal and the first petal; (4) narrow and rounded petal and stamen primordia; (5) delayed development of the petals; (6) appearance of two knobs at the ventral base of the petals before the spurs appear (the knobs appear after the spurs appear in Semiaquilegia, Tucker and Hodges 2005); (7) centripetal stamen initiation and centrifugal anther maturation; (8) floral organs arranged in regular orthostichies (somewhat irregular in Semiaquilegia, Tucker and Hodges 2005); (9) staminodes surrounding the carpels; (10) anatropous and bitegmic ovules with the outer integument longer than the inner one (Table 1). 
However, Aquilegia, Urophysa and Semiaquilegia differ in a number of characters (Tucker and Hodges 2005). For instance, Urophysa is distributed over cliffs, fissures of rocks or wet places by streams (vs. in sparse forests, grassy slopes or alongside roads for Semiaquilegia and Aquilegia). Urophysa flowers from February to early April (vs. March to April for Semiaquilegia and May to August for Aquilegia) (Wang et al. 2001). Urophysa has a mid-sized flower (2 cm in diameter), 30 stamens, 10 staminodes, and eight to 14 stamens. In Semiaquilegia, the flower is minute-sized with 4-6 $\mathrm{mm}$ in diameter, and the staminodes are fewer in number or absent. The flower sizes vary among species of Aquilegia (also see Tucker and Hodges 2005). Urophysa has blue sepals and yellow petals (vs. white sepals and yellow peals in Semiaquilegia and dramatic variation in Aquilegia). The petals of $U$. rockii are ca. $2 \mathrm{~mm}$ in length, and $U$. henryi has no spur (vs. saccate spurs in Semiaquilegia and long spurs in Aquilegia except in A. ecalcarata Maxim., which has no spur and only a nectar-sac near the base) (Wang et al. 2001; Wang and Chen 2007). Therefore, Urophysa shows similar floral developmental features as Aquilegia and Semiaquilegia although with some differences, which support their relationship inferred by DNA sequence data (Wang and Chen 2007).

Acknowledgements: We sincerely thank Professor Carol C. Baskin (University of Kentucky) for helpful comments and for careful reading of the manuscript. We are very grateful to Y.-H. Xiao at Institute of Botany, Chinese Academy of Sciences and Dr. G. F. Guo and X. H. He at Northwest A\&F University for assistance with SEM. This project was supported by grants from the National Natural Science Foundation of China (\#31300158, \#31100141), the Fundamental Research Funds for the Central Universities (\# QN2012020, 2452015406), the Specialized Research Fund for the 
Doctoral Program of Higher Education of China (\#20120204120032), Scientific Research

Foundation for Doctoral Scholars of Northwest A\&F University (\#Z109021118), and the Special

Scientific Research Foundation of Shaanxi Province.

\section{References:}

APG 2003. An update of the angiosperm phylogeny group classification for the orders and families of flowering plants: APG II. Bot. J. Linn Soc. 141(4): 399-436.

Chang, H.L., Ren, Y., and Lu, A.M. 2005. Floral morphogenesis of Anemone rivularis Buch.-Ham. ex DC. var. flore-minore Maxim. (Ranunculaceae) with special emphasis on androecium development sequence. J. Integr. Plant. Biol. 47(3): 257-263.

Drummond, J.R., and Hutchinson, J. 1920. A revision of Isopyrum (Ranunculaceae) and its nearer allies. Bull. Misc. Inform. Kew. 1920(5): 145-169.

Du, B.G., and Yang, F.L. 2010. Urophysa rockii Ulbr., a rare and endangered plant needs urgent conservation. Curr. Sci. 99(4): 419-420.

Du, G.B., Zhu, D.Y., Yang, Y.J., Shen, J., Yang, F.L., and Su, Z.Y. 2010. Living situation and protections strategies of endangered Urophysa rockii. Jiangsu Agric. Sci. 1: 324-325.

Endress, P.K. 1995. Floral structure and evolution in Ranunculanae. Plant Syst. Evol. 9(Suppl.): $47-61$.

Erbar, C. 2014. Nectar secretion and nectaries in basal angiosperms, magnoliids and non-core eudicots and a comparison with core eudicots. Plant Divers. Evol. 131(2): 63-143.

Erbar, C.P., Kusma, S.K., and Leins, P. 1998. Development and interpretation of nectary organs in Ranunculaceae. Flora 194(3): 317-332. 
Erbar, C., and Leins, P. 2013. Nectar production in the pollen flower of Anemone nemorosa in comparison with other Ranunculaceae and Magnolia (Magnoliaceae). Org. Divers. Evol. 13(3): 287-300.

Feng, M., Fu, D.Z., Liang, H.X., and Lu, A.M. 1995. Floral morphogenesis of Aquilegia L. (Ranunculaceae). Acta Bot. Sin. 37(10): 791-794.

Hiepko, P. 1965. Vergleichend-morphologische und entwick- lungsgeschichtliche Untersuchungen über das Perianth bei den Polycarpicae. Bot. Jahrb. Syst. 84(4): 359-508.

Hodges, S.A. 1997. Floral nectar spurs and diversification. Int. J. Plant Sci. 158(6 Suppl.): 81-88.

Kosuge, K. 1994. Petal evolution in Ranunculaceae. Plant Syst. Evol. 8(Suppl): 185-191.

Kosuge, K., and Tamura, M. 1989. Ontogenetic studies on petals of the Ranunculaceae. J. Jap. Bot. 64(3): $65-74$.

Kramer, E.M. 2009. Aquilegia: a new model for plant development, ecology, and evolution. Annu. Rev. Plant Biol. 60: 261-277.

Liu, Y.Q., Liu, G., Zhao, X., Zhang, Q., and Liu, Y. 2007. Biological and ecological characteristics and cultivation experiments of Urophysa rockii. J. Sichuan Forest Sci. Technol. 28(2): 47-48.

Liu, Y.Q., Xu, Z.Y., Zhao, X., Zhang, Q., and Liu, G. 2009. Living environment and cultivation experiments of Urophysa rockii. China Seed Industr. 2: 69-70.

Prenner, G., Bateman, R.M., and Rudall, P.J. 2010. Floral formulae updated for routine inclusion in formal taxonomic descriptions. Taxon 59(1): 241-250.

Ren, Y., Chang, H.L., and Endress, P.K. 2010. Floral development in Anemoneae (Ranunculaceae). Bot. J. Linn. Soc. 162(1): 77-100.

Ren, Y., Chang, H.L., Tian, X.H., Song, P., and Endress, P.K. 2009. Floral development in 
Adonideae (Ranunculaceae). Flora 204(7): 506-517.

Ren, Y., Gu, T.Q., and Chang, H.L. 2011. Floral development of Dichocarpum, Thalictrum, and Aquilegia (Thalictroideae, Ranunculaceae). Plant Syst. Evol. 292(3): 203-213.

Ronse De Craene, L.P. 2010. Floral diagrams: an aid to understanding flower morphology and evolution. Cambridge University Press, Cambridge.

Ronse De Craene, L.P., Soltis, D.E., and Soltis, P.S. 2003. Evolution of floral structures in the basal angiosperms. Int. J. Plant Sci. 164(5 Suppl.): 329-363.

Schöffel, K. 1932. Untersuchungen über den Blütenbau der Ranunculaceen. Planta 17(2): $315-371$.

Sharma, B., Yant, L., Hodges, S.A., and Kramer, E.M. 2014. Understanding the development and evolution of novel floral form in Aquilegia. Curr. Opin. Plant Biol. 17: 22-27.

Song, P., Tian, X.H., and Ren, Y. 2007. Floral morphogenesis of Caltha and Trollius (Ranunculaceae) and the systematic significance. Acta Phytotax. Sin. 45(6): 769-782.

Tamura, M. 1995. Ranunculaceae. In Die natürlichen Pflanzenfamilien, 3nd edn. Edited by P. Hiepko. Vol. 17a (4). Duncker und Humblot, Berlin.

Tepfer, S.S. 1953. Floral anatomy and ontogeny in Aquilegia formosa var. truncata and Ranunculus repens. Univ. California Publ. Bot. 25(7): 513-648.

Tucker, S.C., and Hodges, S.C. 2005. Floral ontogeny of Aquilegia, Semiaquilegia, and Enemion (Ranunculaceae). Int. J. Plant Sci. 166(4): 557-574.

Ulbrich, E. 1929. Ranunculaceae novae vel criticae VIII. Notizbl. Bot. Gart. Berl. 10: 866-871. Voelckel, C., Borevitz, J., Kramer, E.M., and Hodges, S.A. 2010. Within and between whorls: comparative transcriptional profiling of Aquilegia and Arabidopsis. PLoS One 5: e9735. 
Wang, J.X., and He, X.J. 2011. Preliminary study on Urophysa rockii. I. Literature research and biological characteristics of Urophysa rockii. J. Sichuan Forest Sci. Technol. 32(3): 69-73.

Wang, J.X., He, X.J., Xu, W., Meng, W.K., and Su, Z.Y. 2011. Preliminary study on Urophysa rockii. II. Biological characteristics, ecological characteristics and community analysis. J. Sichuan Forest. Sci. Technol. 32(4): 28-39.

Wang, W.T. 2001. Flora of China, Vol. 6. Science Press, Beijing; Missouri Botanical Garden Press, St. Louis, pp. 133-438.

Wang, W., and Chen, Z.D. 2007. Generic level phylogeny of Thalictroideae (Ranunculaceae)— implications for the taxonomic status of Paropyrum and petal evolution. Taxon 56(3): 811-821.

Wang, W., Lu, A.M., Ren, Y., Endress, M.E., and Chen, Z.D. (2009) Phylogeny and classification of Ranunculales: evidence from four molecular loci and morphological data. Perspect. Plant Ecol. Evol. Syst. 11(2): 81-110.

Wang, Z.F., and Ren, Y. 2008. Ovule morphogenesis in Ranunculaceae and its systematic significance. Ann. Bot. 101(3): 447-462.

Zhang, Y.X., Hu, H.Y., and He, X.J. 2013a. Genetic diversity of Urophysa rockii Ulbrich, an endangered and rare species, detected by ISSR. Acta Bot. Boreal. -Occid. Sin. 33(6): $1098-1105$.

Zhang, Y.X., Hu, H.Y., Yang, L.J., Wang, C.B., and He, X.J. 2013b. Deed dispersal and germination of an endangered and rare species Urophysa rockii (Ranunculaceae). Pl. Divers. Resources 35(3): 303-309.

Zhao, L., Bachelier, J.B., Chang, H.L., Tian, X.H., and Ren, Y. 2012a. Inflorescence and floral development in Ranunculus and three allied genera in Ranunculeae (Ranunculoideae, 
Ranunculaceae). Plant Syst. Evol. 298(6): 1057-1071.

Zhao, L., Liu, P., Che, X.F., Wang, W., and Ren, Y. 2011. Floral organogenesis of Helleborus thibetanus and Nigella damascena (Ranunculaceae) and its systematic significance. Bot. J. Linn. Soc. 166(4): 431-443.

Zhao, L., Wang, W., Ren, Y., Bachelier, J.B. 2012b. Floral development in Asteropyrum (Ranunculaceae): implication for its systematic position. Ann. Bot. Fenn. 49(1-2): 31-42. 
Table 1 Comparison of floral development of Urophysa, Aquilegia, Semiaquilegia, Thalictrum, and Dichocarpum

\begin{tabular}{|c|c|c|c|c|c|}
\hline Character & Urophysa & Aquilegia & Semiaquilegia & Thalictrum & Dichocarpum \\
\hline Floral phyllotaxis & whorled & whorled & whorled & irregularly whorled & whorled \\
\hline \multicolumn{6}{|l|}{ Sepal } \\
\hline Initiation & spirally & spirally & spirally & in two pairs or spirally & spirally \\
\hline \multirow[t]{2}{*}{ Primordium shape } & broad and & broad and & broad and & broad and & broad and \\
\hline & crescent-shaped & crescent-shaped & crescent-shaped & crescent-shaped & crescent-shaped \\
\hline \multirow[t]{2}{*}{ Petal } & spurred, with nectary tissue & spurred, with nectary tissue & spurred, with nectary tissue & none & goblet-like, with nectary tissue \\
\hline & secreted at the base & secreted at the base & secreted at the base & & secreted at the base \\
\hline \multicolumn{6}{|l|}{ Stamen } \\
\hline Primordium shape & rounded & rounded & rounded & rounded & rounded \\
\hline Arrangement & regular orthostichies & regular orthostichies & irregular orthostichies & irregular orthostichies & irregular orthostichies \\
\hline Staminodes & $\begin{array}{l}10 \text {, present between sepals } \\
\text { and fertile stamens }\end{array}$ & $\begin{array}{l}\text { 10, present between sepals } \\
\text { and fertile stamens }\end{array}$ & $\begin{array}{l}2-4 \text {, present between sepals } \\
\text { and fertile stamens }\end{array}$ & none & none \\
\hline Maturation direction & centrifugal & centrifugal & $?$ & centripetal & centripetal \\
\hline \multicolumn{6}{|l|}{ Carpel } \\
\hline Development & plicate & plicate & plicate & ascidiate & plicate \\
\hline \multicolumn{6}{|l|}{ Ovule } \\
\hline Curvature & anatropous & anatropous & anatropous & anatropous & anatropous \\
\hline Integuments & bitegmic & bitegmic & bitegmic & bitegmic & bitegmic \\
\hline Appendage & $\begin{array}{l}\text { appears from the placenta and } \\
\text { the funiculus; outer } \\
\text { integument is longer than } \\
\text { inner one }\end{array}$ & $\begin{array}{l}\text { appears from the placenta and } \\
\text { the funiculus; funiculus } \\
\text { completely fuses with ovule } \\
\text { body; outer integument is } \\
\text { longer than inner one }\end{array}$ & $\begin{array}{l}\text { appears from the placenta and } \\
\text { the funiculus; funiculus } \\
\text { completely fuses with ovule } \\
\text { body; outer integument is } \\
\text { longer than inner one }\end{array}$ & $\begin{array}{l}\text { appears from the placenta } \\
\text { and the funiculus; funiculus } \\
\text { completely fuses with ovule } \\
\text { body; inner integument is } \\
\text { longer than outer one }\end{array}$ & $\begin{array}{l}\text { appendage appears on the upper } \\
\text { part of the ventral side of the } \\
\text { funiculus; two-thirds of the } \\
\text { funicle fuses with ovule body; } \\
\text { outer integument is longer than } \\
\text { inner one }\end{array}$ \\
\hline
\end{tabular}


Note. Flower morphological and developmental character states of Urophysa are taken from this study; those of Aquilegia, Semiaquilegia, Thalictrum, and Dichocarpum from Feng et al. (1995), Tucker and Hodges (2005), Ren et al. (2011) and Wang and Ren (2008) 


\section{Legends}

Fig. 1 Habitat, mature flower, floral diagram and floral formula of Urophysa rockii

\section{Ulbrich}

A-B. Habitat, plants in flower (mid-February). C. Anthetic flower. D. Floral diagram and floral formula. Black dot indicates floral axis; black arcs indicate sepals; grey arcs indicate petals; four closed circles indicate stamens; four closed dots indicate staminodes and ellipses indicate ovaries. Scale bars: $\mathrm{B}, \mathrm{C}=1 \mathrm{~cm}$

\section{Fig. 2 Floral development of Urophysa rockii Ulbrich}

A. Initiation of the five crescent-shaped and truncate sepal primordia. B. Initiation of petals, showing hemispherical and rounded primordia. C-D. Initiation of stamens, showing primordia with a shape similar to that of petals. E. Side view of stamen orthostichies and staminode primordia from the top of each orthostichy. F. Same stage as Fig. 2E in top view. G. Initiation of carpels, and petals are smaller than stamens at this stage. H-J. Development of carpels, stamens are gradually differentiated into filaments and anthers. K. Showing staminodes and delayed petal formation. L. Showing delayed petal formation and stamen orthostichies.

Abbreviations: $\mathrm{C}=$ carpel; $\mathrm{P}=$ petal; $\mathrm{S}=$ sepal; $\mathrm{Ss}=$ staminode; $\mathrm{St}=$ stamen. Numbers after the letters indicate initiation sequence. Scale bars: $100 \mathrm{um}$

\section{Fig. 3 Floral development of Urophysa rockii Ulbrich}

A-D. Development of petal. A. Petal primordium with two bulges (arrows), from ventral side. B.

Slightly later stage, two bulges enlarged and fused. C-D. The center of the petal becoming deeper 
and begining to form as a pocket. E. Stamen. F. Showing the basifixed and longitudinal dehiscent anthers. G. Inner stamen with broad and wrinkled filament. H. Tricolpate pollen. I-K.

Development of the staminodes. L-P. Development of the carpels.

Abbreviations: $\mathrm{P}=$ petal; $\mathrm{Ss}=$ staminode. Scale bars: A-D, $\mathrm{L}-\mathrm{P}=100 \mathrm{um} ; \mathrm{E}-\mathrm{G}=1 \mathrm{~mm} ; \mathrm{H}=10 \mathrm{um}$; $\mathrm{I}-\mathrm{K}=300 \mathrm{um}$.

Fig. 4 Anatomy and ultrastructure of flower and floral nectary in Urophysa rockii Ulbrich

A. Anatomy of the flower, showing the filament of the stamen, staminode and carpel. B.

Longitudinal section of the petal, showing the nectary at the base of the petal. C-E. Serial sections of the petal, showing that the nectary is inside the spur. F. Close-up of Fig. 4D, showing the secretory tissue.

Abbreviations: $\mathrm{C}=$ carpel; $\mathrm{St}=$ stamen; $\mathrm{N}=$ nectary; $\mathrm{PH}=$ phloem; $\mathrm{Ss}=$ staminode. Scale bars: $\mathrm{A}$, B, C-E =100um; F =50um

Fig. 5 Longitudinal section of three stamens in an orthostichy of Urophysa rockii Ulbrich, showing sequence of microsporogenesis

A. A flower, showing three stamens in an orthostichy. B-D. Close-up of microspore sacs. B. St, pollens formed. C. $\mathrm{St}_{2}$, stage after tetrad. $\mathrm{D} . \mathrm{St}_{3}$, stage of tetrad. Abbreviations: $\mathrm{St}=$ stamen. Scale bars: A = 1mm; B-D = 100um.

Fig. 6 Ovule morphogenesis in Urophysa rockii Ulbrich

A. Ovule primordia. B. Initiation of annular inner integument, from above. C. The ovule starts to 
bend inwards, from the side. D. Initiation of semi-annular outer integument. E. Cup-shaped inner integument and hood-shaped outer integument. F. Inner integument longer than the outer, appendage appears at the base of the ventral side of the funiculus and on the placenta. G-H. The appendage continues growing and increasing in length. I. Mature ovule, showing micropyle with lobed inner integument. Abbreviations: $\mathrm{A}=$ appendage; $\mathrm{F}$ = funiculus; $\mathrm{II}=$ Inner integument; $\mathrm{N}=$ Nucellus; $\mathrm{O}=$ Ovule primordium; $\mathrm{OI}=$ Outer integument. Scale bars: $50 \mu \mathrm{m}$. 

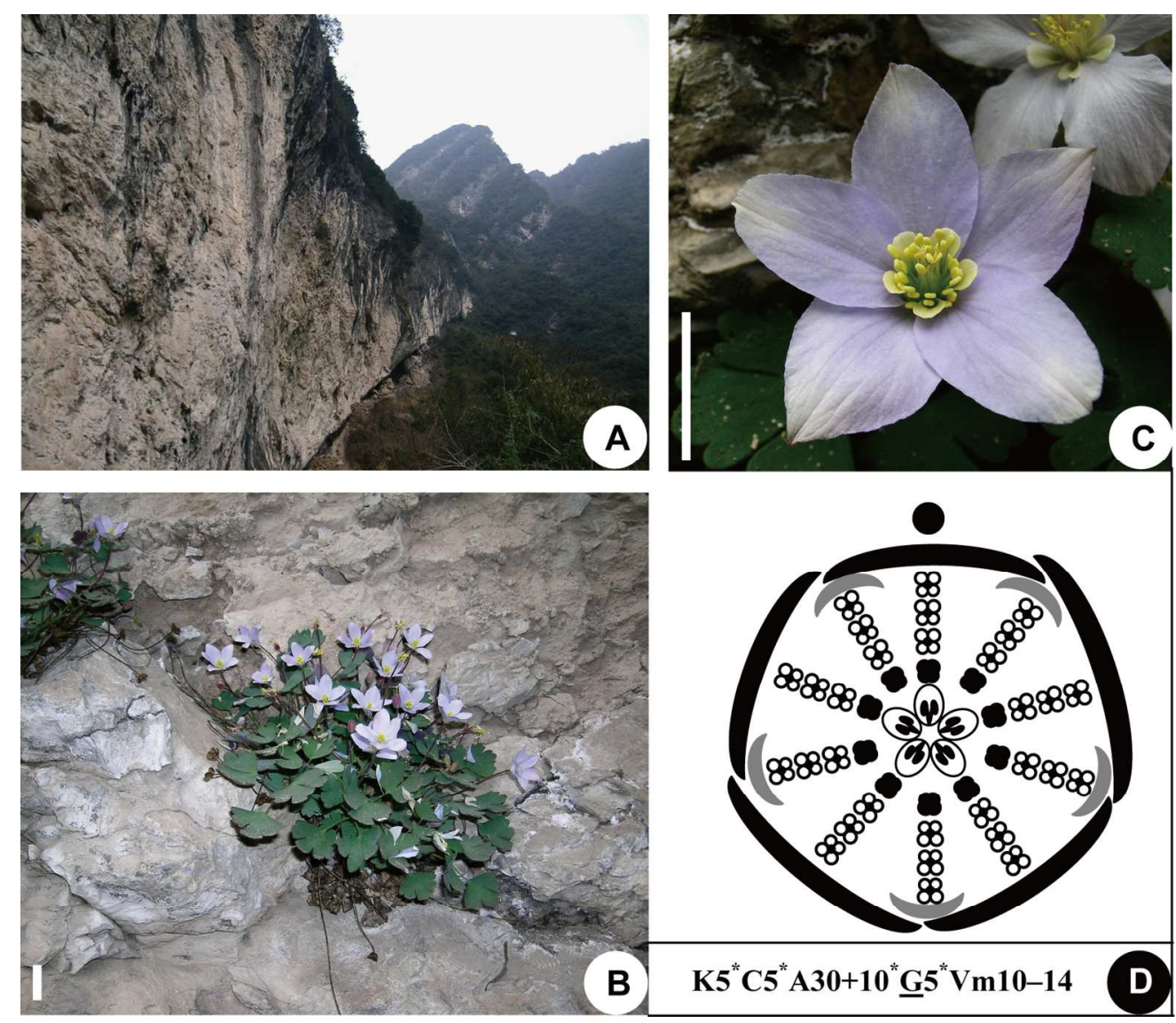

$139 \times 121 \mathrm{~mm}(300 \times 300 \mathrm{DPI})$ 


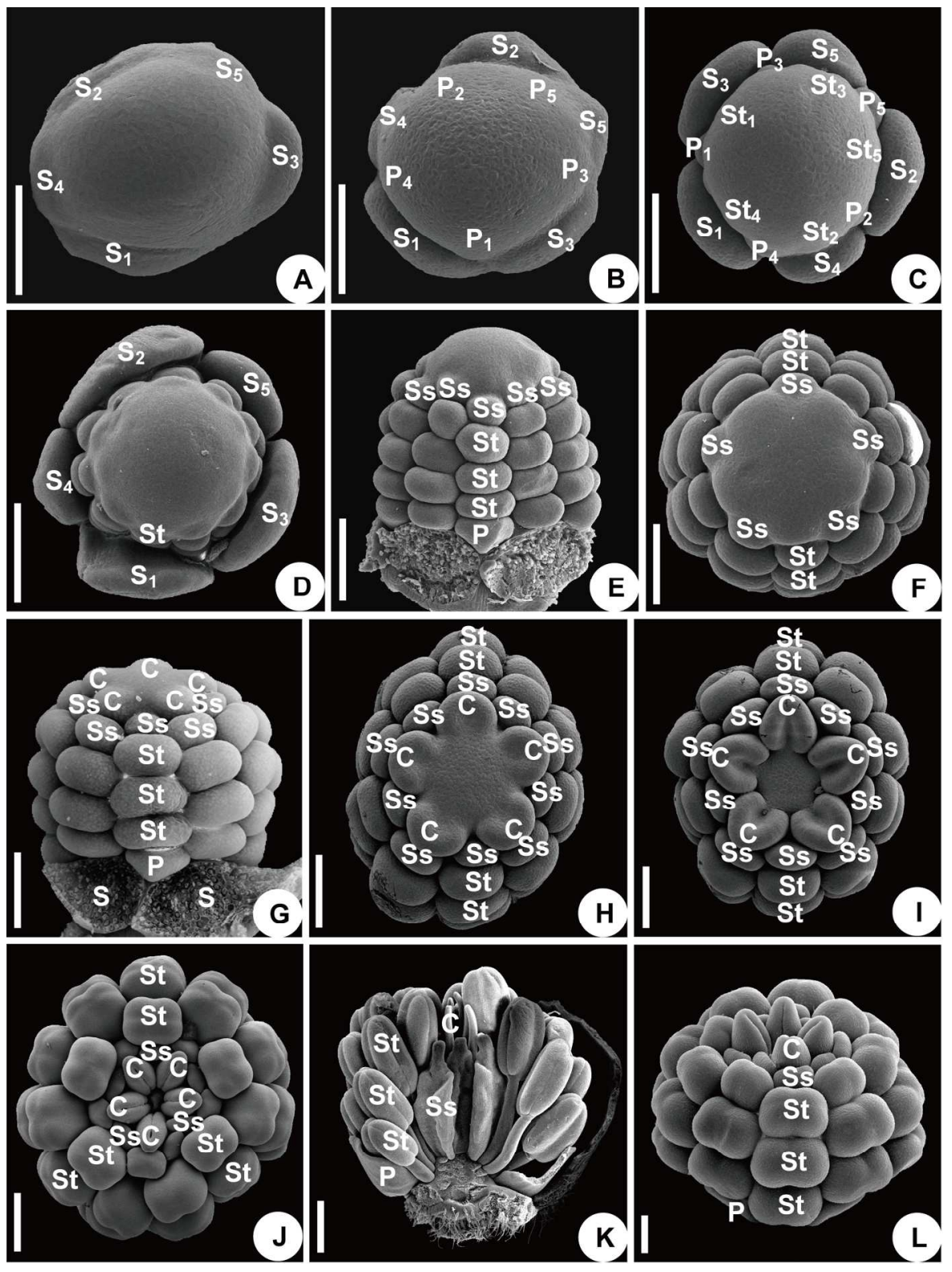

$146 \times 196 \mathrm{~mm}(300 \times 300 \mathrm{DPI})$ 

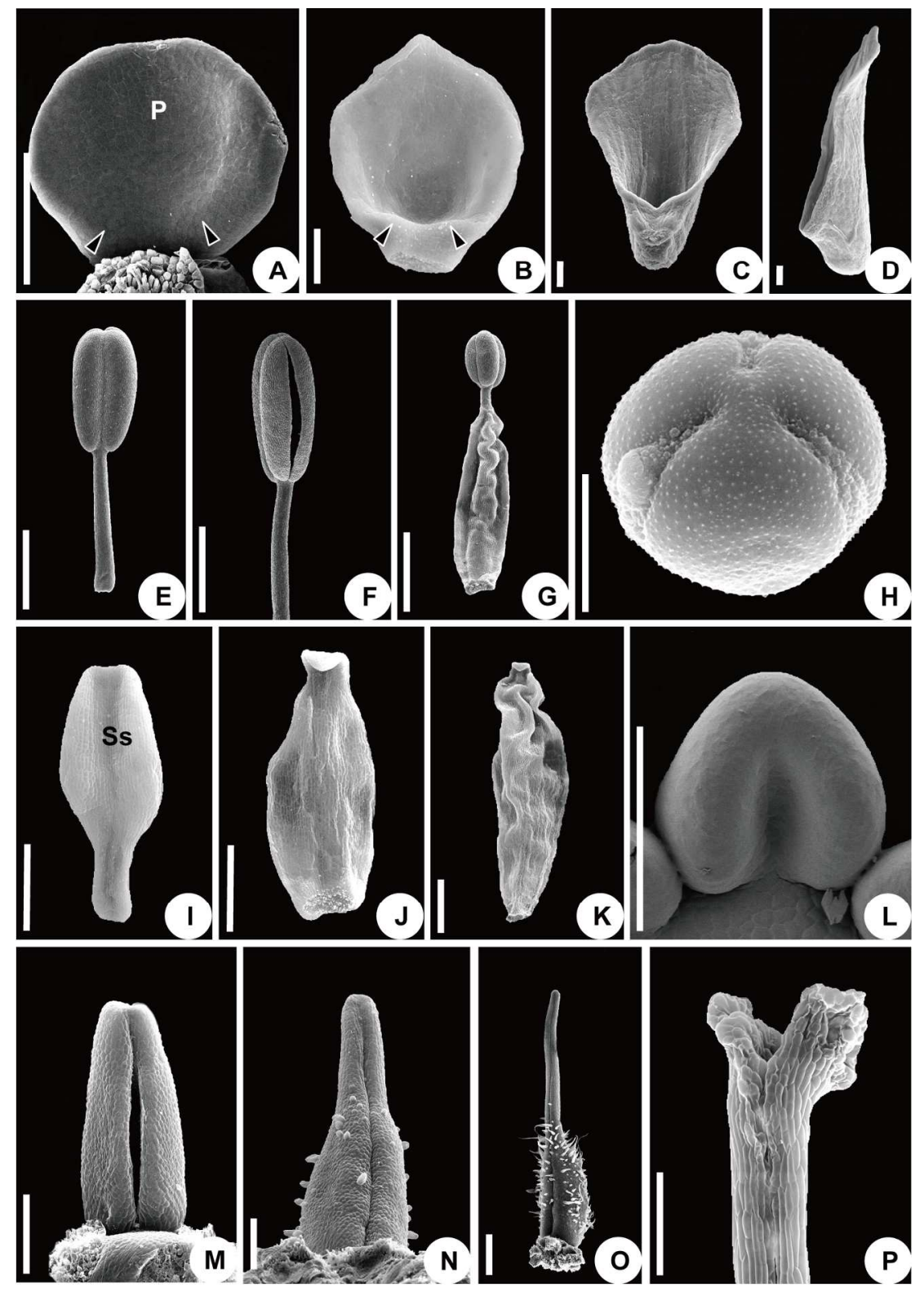

$146 \times 209 \mathrm{~mm}(300 \times 300 \mathrm{DPI})$ 

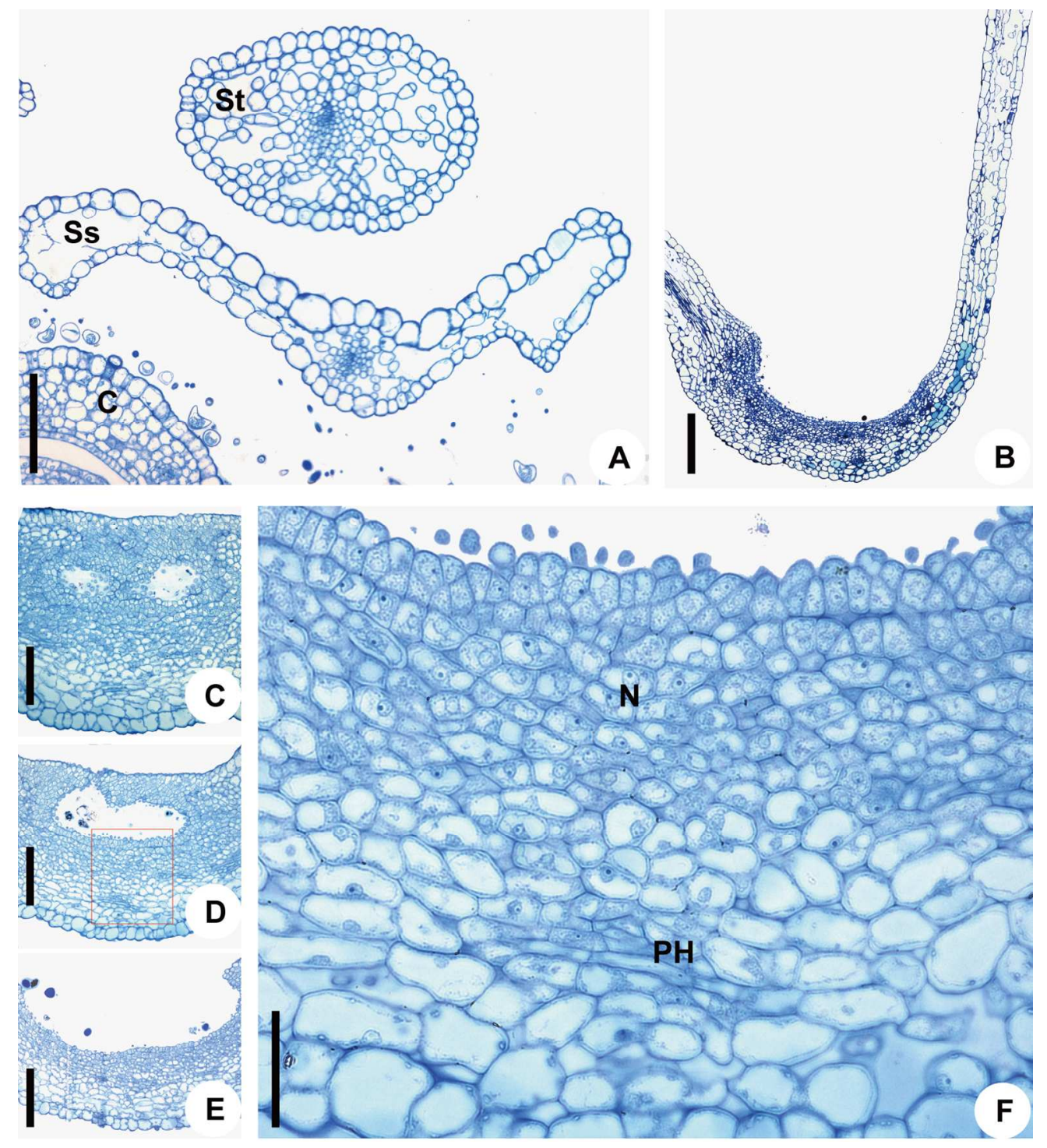

$139 \times 155 \mathrm{~mm}(300 \times 300$ DPI $)$ 


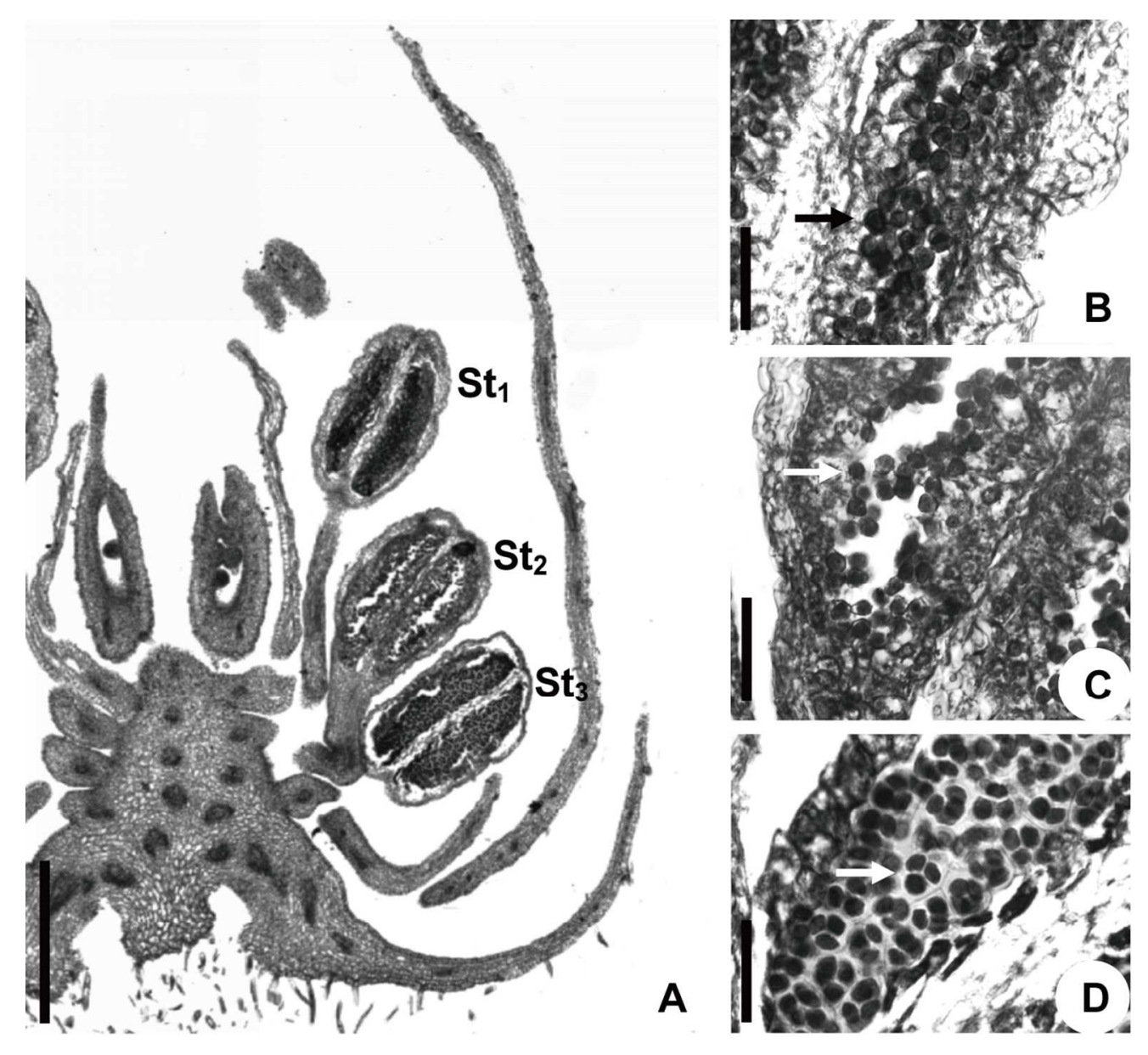

$115 \times 105 \mathrm{~mm}(300 \times 300 \mathrm{DPI})$ 

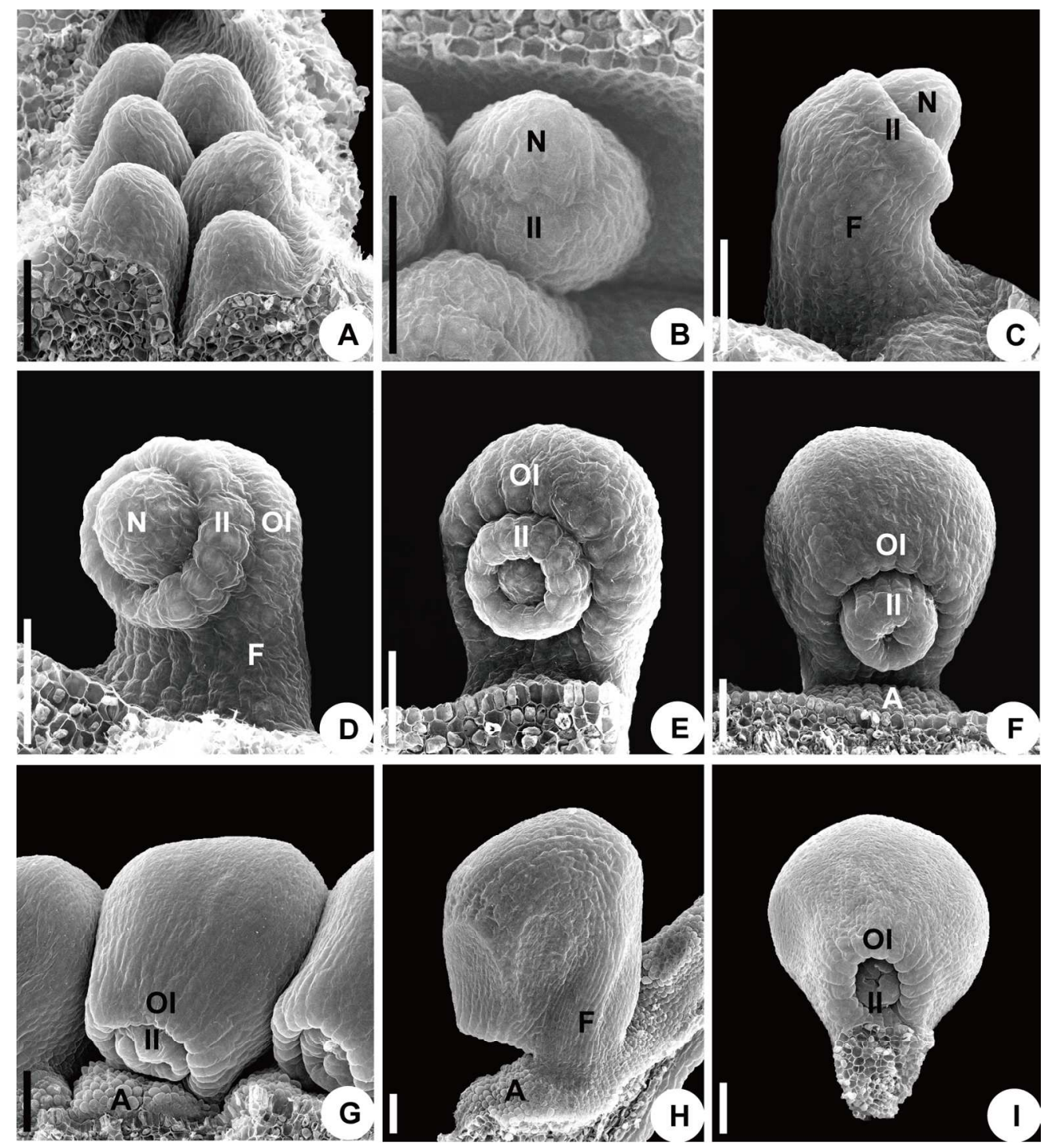

$146 \times 162 \mathrm{~mm}(300 \times 300$ DPI $)$ 